\title{
Pengaruh Penambahan Bahan Redam pada Kebocoran Alat Ukur Daya Isolasi Bahan
}

\author{
Didiek Basuki Rahmat,* Alpha Hambally Armen, dan Gontjang Prajitno ${ }^{\dagger}$ \\ Jurusan Fisika-FMIPA, Intitut Teknologi Sepuluh Nopember \\ Kampus ITS Sukolilo, Surabaya 60111
}

\begin{abstract}
Intisari
Telah dilakukan penelitian tentang penambahan bahan redam untuk mengurangi kebocoran pada alat ukur daya isolasi bahan. Alat ukur daya isolasi ini dapat mengetahui nilai Insertion Loss dan Noise Reduction dari suatu bahan. Penelitian ini adalah melakukan sebuah pembuatan box yang dirancang untuk menutupi semua bagian alat ukur daya isolasi bahan ini, box terbuat dari bahan gypsum yang ditambah dengan kombinasi bahan redam yaitu rockwoll dan karpet, kondisi alat sebelumnya, tingkat kebocoran dari dalam alat mencapai $24 \mathrm{~dB}$ sampai dengan $33 \mathrm{~dB}$, dengan adanya box dan penambahan bahan redam ini, tingkat kebocoran dapat dikurangi. Dengan tiga variasi bahan redam yaitu karpet, rockwoll dan rockwoll ditambah karpet nilai kebocoran dapat diminimalisir, sehingga mencapai $5 \mathrm{~dB}$ samapai dengan $15 \mathrm{~dB}$. Alat ukur daya isolasi bahan ini dapat melakukan pengukuran dengan sumber bunyi $90 \mathrm{~dB}$ sampai $100 \mathrm{~dB}$ dibuktikan dengan pengukuran nilai Insertion Loss dan Noise Reduction yang telah dilakukan. Tidak ada pengaruh pada pengukuran ketika digunakan dua sumber bunyi tersebut.
\end{abstract}

\begin{abstract}
A study has been done that is adding damping materials to reduce leakage power gauge insulation materials. This instrument can determine the value of Insertion Loss and Noise Reduction of a material. This study was conducted a box-making are designed to cover all parts of insulating material power gauge, the box is made of gypsum is added to the combination of damping material that is rockwoll and rugs, machine condition before, the leakage rate of the tool reaches $24 \mathrm{~dB}-33 \mathrm{~dB}$, with the box, the rate of leakage can be reduced in accordance. The three variations of damping materials are carpets, rugs plus rockwollrockwoll and leakage values can be minimized by the use of damping carpet plus rockwoll reaches $5 \mathrm{~dB}-15 \mathrm{~dB}$. Insulation materials of power measuring devices can perform measurements with the noise source between $90 \mathrm{~dB}$ to $100 \mathrm{~dB}$ proven by measuring the value of Insertion Loss and Noise Reduction. There is no effect on the measurement when used two sources of sound.
\end{abstract}

KATA KUNCI: daya isolasi, Insertion Loss, reduksi bising, redam.

\section{PENDAHULUAN}

Bunyi merupakan suatu besaran fisis akustik yang dapat terpantul, diserap dan diteruskan. Keras lemahnya besaran bunyi pun berbeda-beda bergantung pada sumber bunyi itu sendiri. Karena faktor keras lemah tersebut terdapat masalah yaitu kebisingan, misalnya di jalan raya yang padat kendaraan di seberangnya terdapat sekolah, itu akan menjadi masalah ketika sekolah tersebut terganggu karena kebisingan di jalan raya.

Bunyi yang menyebabkan kebisingan harusnya di isolasi dengan menggunakan bahan-bahan tertentu. Daya serap bahan tersebut yang mempengaruhi daya isolasinya. Jika daya yang diteruskan tersebut tinggi terlihat bahwa proposional yang diteruskan kecil, begitu sebaliknya jika daya yang diteruskan rendah, proposional yang diteruskan terlihat besar.

\footnotetext{
*E-MAIL: didiek@physics.its.ac.id

${ }^{\dagger}$ E-MAIL: gont jang@physics.its.ac.id
}

Maka daya isolasi sebuah bahan layak diteliti dalam sebuah pengukuran pada Sound Transmission Loss.

Untuk melakukan pengukuran besaran Transmission Loss ini, diperlukan biaya yang tidak sedikit karena ruangan uji harus dirancang sedemikian rupa untuk dapat melakukan pengukuran.

Ansarullah [1] telah membuat alat tentang daya isolasi yang mengacu pada metode ASTM E2611-09 [2]. Pada alat tersebut digunakan tabung sumber dan tabung penerima yang berfungsi menerima bunyi yang tembus melalui bahan uji. Bahan uji diletakkan di antara tabung sumber dan tabung penerima. Hasil pengukuran masih menunjukkan adanya kebocoran pada tabung pengirim dan tabung penerimanya. Permasalahan ini harus ditangani, karena akan berpengaruh pada hasil pengukuran. Pada artikel ini dilaporkan hasil penelitian pengaruh penambahan bahan redam terhadap kebocoran pada alat ukur daya isolasi bahan. 


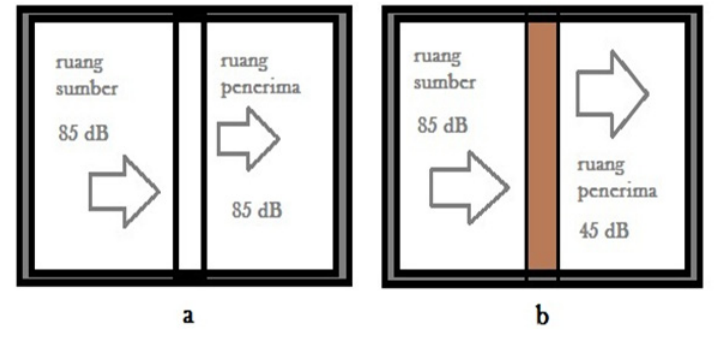

Gambar 1: Perbedaan tingkat tekanan bunyi di ruang penerima dan ruang sumber.

\section{TEORI DASAR}

\section{Transmission Loss}

Faktor yang dinilai pada karakteristik suatu bahan akustik adalah nilai transmission loss material akustik, yaitu kemampuan bahan untuk tidak meneruskan bunyi atau mengisolasi bunyi dari suatu ruang sumber bunyi. Untuk dapat mengisolasi bunyi diperlukan bahan yang memiliki transmission loss yang tinggi. Jumlah energi yang ditransmisikan dibagi dengan energi datang dinyatakan sebagai besaran koefisien transmisi $\tau$.

Transmission Loss menyatakan besarnya energi yang hilang karena gelombang bunyi melewati suatu partisi [3], yang dinyatakan dalam decibel. Hubungan antara koefisien transmisi dengan transmission loss dapat dituliskan dalam persamaan:

$$
T L=10 \log \frac{1}{\tau} d B
$$

dengan $\tau$ adalah koefisien transmisi.

\section{Insertion Loss dan Noise Reduction}

Insertion Loss adalah ukuran yang digunakan untuk menentukan seberapa baik sebuah partisi mengurangi kebisingan bunyi. Sebagai gambaran dapat dilihat pada Gambar 1. Pada Gambar 1 (a) tidak diberi partisi, sedangkan pada Gambar 1 (b) diberi partisi. Pada saat sumber bunyi dinyalakan terlihat perbedaan tingkat tekanan bunyi di ruang penerima. Di ruang penerima Gambar (a) dan (b) yang awal mulanya $85 \mathrm{~dB}$ menjadi $45 \mathrm{~dB}$ setelah diberi partisi. Hal ini terjadi karena adanya partisi. Selanjutnya, ditentukan Insertion Loss (IL) sebagai [4]:

$$
I L=S P L_{a}-S P L_{b}
$$

dengan $\mathrm{SPL}_{a}=$ tingkat tekanan bunyi di ruang penerima tanpa partisi, $\mathrm{SPL}_{b}=$ tingkat tekanan bunyi di ruang penerima dengan partisi.

Besaran lain yang juga digunakan untuk menyatakan daya isolasi suatu bahan adalah reduksi bising (Noise Reduction).
Reduksi bising terjadi antara ruang sumber bunyi dengan ruang penerima bunyi. Reduksi bising merupakan selisih tingkat tekanan bunyi dalam ruang sumber bunyi dengan tingkat tekanan bunyi dalam ruang penerima seperti pada Gambar 1 . Secara matematis reduksi bising dinyatakan dalam persamaan berikut [5]

$$
N R=S P L_{1}-S P L_{2}
$$

dengan $\mathrm{NR}=$ reduksi bising $(\mathrm{dB}), \mathrm{SPL}_{1}=$ tingkat tekanan bunyi dalam ruang sumber $(\mathrm{dB}), \mathrm{SPL}_{2}=$ tingkat tekanan bunyi dalam ruang penerima $(\mathrm{dB})$.

\section{Metode ASTM-E2611-09}

Pengukuran standar untuk mengetahui daya isolasi bahan sangat banyak, diantaranya adalah ASTM E-90, ASTM E 1050, ISO DIS 140-1, ISO 354. Pada ISO 140, pengukuran melibatkan dua buah ruang sumber dan penerima. Pengukuran dengan ISO 140 membutuhkan ruang yang cukup luas dengan biaya yang mahal. Oleh karena itu, pada penelitian ini di lakukan pembuatan alat ukur daya isolasi bahan sederhana dengan metode tabung uji yang mengacu pada ASTM E2611-09 [2].

ASTM E2611-09 adalah standar pengukuran untuk mengukur sebuah STL menggunakan metode transfer matriks untuk perhitungan. Data untuk perhitungan diperoleh dari pengukuran tekanan suara dari empat mikrofon, dua diposisikan antara sumber suara dan bahan uji dan dua diposisikan di sisi berlawanan dari bahan uji. Metode menentukan geometri dari alat uji yang diperlukan sehubungan dengan ukuran bahan uji, posisi mikrofon dan rentang frekuensi yang diukur. Suara pengujian peralatan berdasarkan ASTM E2611 09 ditawarkan dalam dua ukuran tabung, satu dengan diameter $100 \mathrm{~mm}$ dan lainnya dengan diameter dari $29 \mathrm{~mm}$. Rentang frekuensi yang diukur adalah $50 \mathrm{~Hz}-1,6 \mathrm{kHz}$ untuk tabung yang lebih besar dan $500 \mathrm{~Hz}-6.4 \mathrm{kHz}$ untuk tabung kecil. Sebuah diagram skematik aparat tabung empat mikrofon ditunjukkan pada Gambar 2.

Ke-empat mikrofon di lokasi tetap (dua dalam tabung sumber dan dua dalam tabung penerima) merekam tekanan suara selama pengambilan data. Ini terhubung ke analyzer empat kanal frekuensi digital yang digunakan untuk menghitung fungsi transfer yang kompleks, alat ini mampu menentukan STL sampel. Hasilnya dapat ditampilkan sebagai suatu skenario frekuensi v STL untuk berbagai ukuran tabung [6, 7].

Pada penelitian ini, metode ASTM E2611-09 beserta alatnya, hanya menjadi acuan dalam penelitian, karena pada penelitian ini peletakkan microphone pada alat masih bisa dapat diubah-ubah, tidak tetap seperti pada metode ASTM E2611-09 yang ada. 


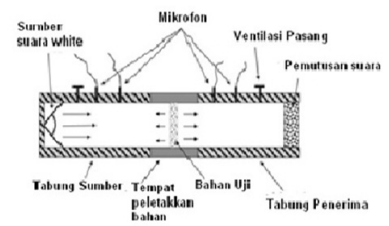

(a)

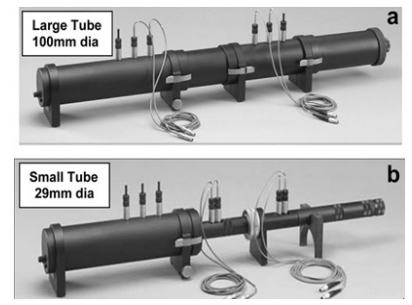

(b)

Gambar 2: a. Metode ASTM E2611-09 [2], b. Alat ukur daya isolasi bahan.

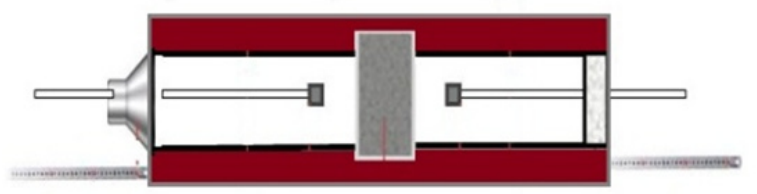

Gambar 3: Rancangan box untuk meredam kebocoran.

\section{METODOLOGI}

\section{Perancangan box untuk menutupi alat ukur daya isolasi bahan}

Alat ukur daya isolasi bahan ini nantinya akan dimasukkan ke dalam sebuah box yang terbuat dari bahan gypsum, box akan dirancang sedemikain rupa agar menutupi semua bagian alat ukur daya isolasi bahan ini, seperti terlihat pada Gambar 3 box tersebut terbuat dari bahan gypsum, dengan panjang 260 $\mathrm{cm}$, lebar dan tinggi $35 \mathrm{~cm}$, pada dinding box ini diberi sedikit rongga, yang bertujuan untuk penambahan bahan redam yang akan diletakkan di antara dinding box dan alat ukur daya isolasi bahan ini.

\section{Perbaikan di bagian kotak speaker bagian mulut tabung}

Selain penambahan box sebagai tingkat kedap, dilakukan pula sedikit perbaikan di bagian kotak speaker. Perbaikan ini bertujuan untuk meredam suara yang keluar dari speaker. Perbaikan yang dilakukan antara lain penambahan bahan dengan kombinasi rockwoll, tempat telur dan karpet, seperti pada Gambar 4.

Selain beberapa hal diatas, dilakukan pula sedikit penambahan rockwoll pada mulut tabung alat ini, hal ini bertujuan

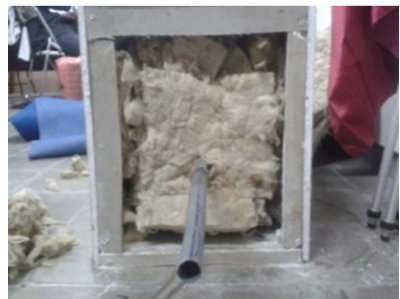

(a)

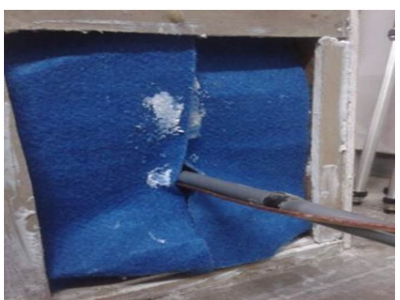

(b)

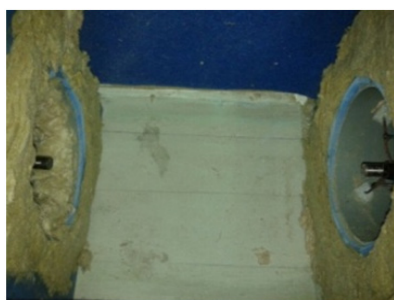

(c)
Gambar 4: Perbaikan pada box speaker dan penambahan rockwoll di mulut tabung.

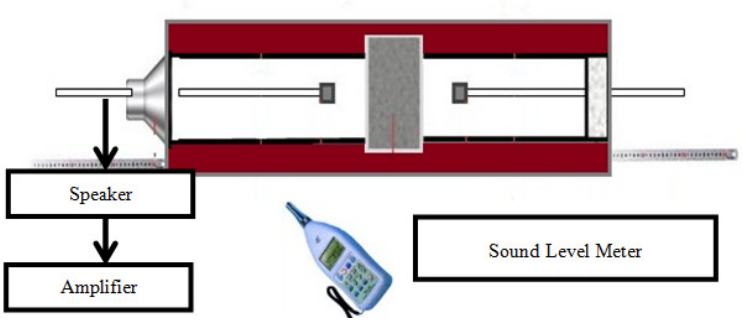

Gambar 5: Skema pengujian tingkat kebocoran.

untuk meredam bunyi yang kemungkinan keluar dari mulut tabung.

\section{Pengujian tingkat kekedapan}

Setelah box terpasang menutupi alat ukur daya isolasi bahan ini, akan dilakukan pengujian tingkat kebocoran dari alat, akan dibangkitkan sumber (white noise) sebesar $80 \mathrm{~dB}, 90$ $\mathrm{dB}$ dan $100 \mathrm{~dB}$ dari dalam tabung. Akan dilakukan pengukuran dibagian luar box tersebut, pengukuran dilakukan dengan penggunaan bahan redam yaitu rockwoll, karpet dan penggabungan kedua bahan tersebut. Skema pengambilan data dapat dilihat pada Gambar 5.

\section{HASIL DAN ANALISIS}

\section{Pengenalan alat beserta box yang telah dirancang}

Box yang dibuat untuk menutupi semua bagian tabung pada alat ukur, box tersebut terbuat dari bahan gypsum, dengan panjang $260 \mathrm{~cm}$, lebar dan tinggi $35 \mathrm{~cm}$. 


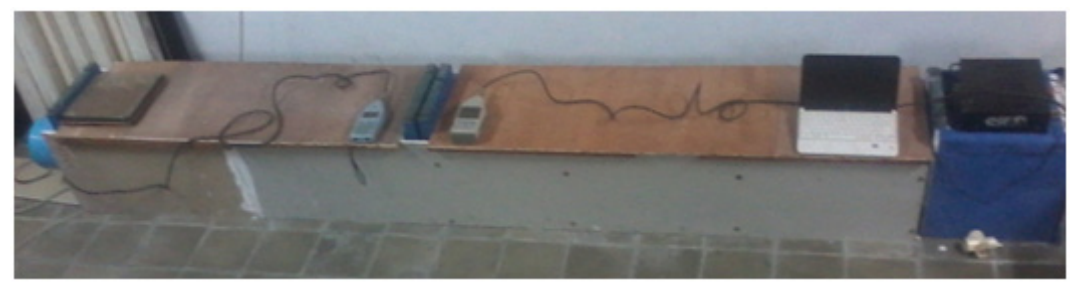

Gambar 6: Alat ukur yang telah dimasukkan ke dalam box.

TABEL I: Hasil uji kebocoran alat [1]

\begin{tabular}{ccccc}
\hline \hline $\begin{array}{c}\text { Frekuensi } \\
(\mathrm{Hz})\end{array}$ & $\begin{array}{c}\text { SPL di dalam } \\
\text { tabung }(\mathrm{dB})\end{array}$ & $\begin{array}{c}\text { SPL di luar } \\
\text { tabung }(\mathrm{dB})\end{array}$ & $\begin{array}{c}\text { Ruangan } \\
(\mathrm{dB})\end{array}$ & $\begin{array}{c}\text { Kebocoran } \\
(\mathrm{dB})\end{array}$ \\
\hline 250 & 100 & $83 \pm 0,3$ & $47-50$ & $33 \pm 0,3$ \\
500 & 100 & $75 \pm 0,2$ & $45-48$ & $33 \pm 0,3$ \\
1000 & 100 & $69 \pm 0,4$ & $43-45$ & $24 \pm 0,4$ \\
2000 & 100 & $69 \pm 0,3$ & $41-43$ & $26 \pm 0,3$ \\
\hline
\end{tabular}

Box gypsum yang dirancang untuk meredam suara juga dilengkapi dengan beberapa bahan tambahan, yaitu karpet dan rockwoll yang menutupi alat ukur daya isolasi ini. Pada pengujian tingkat redam, nantinya akan dicoba satu persatu dari bahan tersebut lalu dicoba juga mengkombinasikan keduanya.

\section{Hasil uji tingkat kekedapan}

Data yang diperoleh dari pengujian alat sebelumnya, diketahui adanya kebocoran yang cukup besar, seperti ditunjukkan pada Tabel 1. Besar kebocoran bisa dilihat dari kondisi luar tabung, yaitu perbandingan kondisi background sebelum dan sesudah diberi bunyi, besar kebocoran ini sangat tinggi, permasalahan ini harusnya ditangani agar tidak ada pengaruh pada pengukuran pengujian partisi nantinya. Pengaruh pada pengukuran disini adalah, ruang penerima dirancang benarbenar menerima sumber bunyi hanya dari ruang sumber, jika ada sebuah kebocoran, hal ditakutkan adalah ruang penerima tidak hanya menerima sumber dari ruang penerima, namun juga pengaruh kebocoran dari luar ruang.

Setelah alat dimasukkan ke dalam box yang telah ditambah oleh lapisan bahan redam (rockwoll, karpet), dilakukan uji kebocoran untuk masing-masing penggunaan bahan redam yaitu rockwoll, karpet dan gabungan keduanya. Hasil pengukuran uji kebocoran ditunjukkan Tabel 2.

Tentang penggunaan bahan redam yaitu karpet dan rockwoll, yang membedakan nilai keduanya adalah besar nilai koefisen absorbsi yang berbeda, lalu ketika digabungkan keduanya, memiliki nilai koefisien absorbsi yang baik daripada penggunaan satu bahan redam. Tekanan bunyi yang ditransmisikan dari bahan redam tersebut juga kembali diredam oleh box (gypsum) yang bersifat reflektif, hal ini akan mengembalikan bunyi ke bahan redam (rockwoll dan karpet) yang dipasang.
Karena penambahan box, serta perbaikan pada kotak speaker, tingkat kebocoran dapat dikurangi. Untuk sumber 90 $\mathrm{dB}$, alat ini tidak ditemukan adanya kebocoran, maka alat bisa

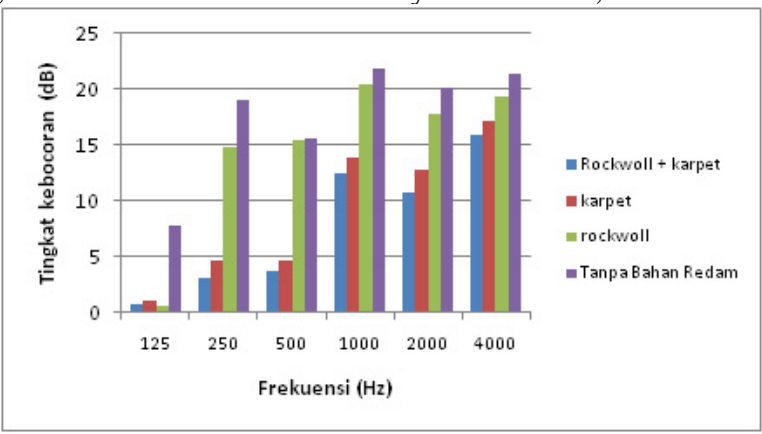

Gambar 7: Grafik perbandingan tingkat kebocoran dengan penggunaan bahan redam dengan sumber di dalam tabung $100 \mathrm{~dB}$.

digunakan dengan sumber bunyi $90 \mathrm{~dB}$ dan $100 \mathrm{~dB}$, untuk membandingkan hasil ini, kita melakukan sebuah pengukuran Noise reduction untuk 2 bahan uji, yaitu triplek dan kaca. Hasil pengujian ditunjukkan pada Tabel 3.

Berdasarkan Tabel 3, tidak ditemukan pengaruh pengukuran jika menggunakan sumber $90 \mathrm{~dB}$ dan $100 \mathrm{~dB}$, karena perbedaan hanya berkisar $\pm 1 \mathrm{~dB}$. Maka alat ini dapat beroperasi, dengan kriteria sumber bunyi $90 \mathrm{~dB}$ sampai dengan 100 dB. Tingkat kebocoran ketika sumber $100 \mathrm{~dB}$, berhasil dikurangi, karena sebelumnya alat ini memiliki kebocoran yang besar $\pm 20 \mathrm{~dB}$. Meskipun tidak meredam 100\% namun kebocoran yang masih ada tidak berpengaruh apa-apa terhadap pengukuran nantinya.

\section{SIMPULAN}

Alat ukur daya isolasi bahan ini dapat melakukan pengukuran dengan sumber tekanan bunyi (white noise) $90 \mathrm{~dB}$ sampai 100 dB. Dengan penggabungan dua bahan redam besar tingkat kebocoran pada alat dapat diredam jika dibandingkan dengan hanya satu bahan redam saja. Perbedaan penggunaan sumber bunyi tidak berpengaruh pada pengukuran Noise reduction, karena dengan dua sumber hasil yang didapatkan hasil yang sama. 
TABEL II: Hasil pengujian tanpa bahan redam.

\begin{tabular}{|c|c|c|c|c|c|c|c|c|c|}
\hline \multirow{2}{*}{$\begin{array}{l}\text { Frekuensi } \\
(\mathrm{Hz})\end{array}$} & \multirow{2}{*}{$\begin{array}{c}\text { SPL di dalam } \\
\text { tabung }(\mathrm{dB})\end{array}$} & \multicolumn{2}{|c|}{ tanpa bahan redam } & \multicolumn{2}{|c|}{ bahan redam karpet } & \multicolumn{2}{|c|}{ bahan redam rockwoll } & \multicolumn{2}{|c|}{ bahan redam rockwoll dan karpet } \\
\hline & & $\begin{array}{l}\text { SPL di luar } \\
\text { tabung }(\mathrm{dB})\end{array}$ & $\begin{array}{c}\text { Background } \\
\text { Noise }(d B)\end{array}$ & $\begin{array}{l}\text { SPL di luar } \\
\text { tabung }(\mathrm{dB})\end{array}$ & $\begin{array}{c}\text { Background } \\
\text { Noise }(\mathrm{dB})\end{array}$ & $\begin{array}{l}\text { SPL di luar } \\
\text { tabung }(\mathrm{dB})\end{array}$ & $\begin{array}{c}\text { Background } \\
\text { Noise }(\mathrm{dB})\end{array}$ & $\begin{array}{l}\text { SPL di luar } \\
\text { tabung }(\mathrm{dB})\end{array}$ & $\begin{array}{l}\text { Background } \\
\text { Noise }(\mathrm{dB})\end{array}$ \\
\hline All & 100 & 64,1 & $58-61$ & 59,5 & $55-60$ & 62,6 & $55-58$ & 62,4 & $58-61$ \\
\hline 125 & 100 & 49,8 & $39-42$ & 49,1 & $45-48$ & 45,7 & $42-45$ & 50,8 & $47-50$ \\
\hline 250 & 100 & 56 & $35-37$ & 50,7 & $40-46$ & 52,9 & $35-38$ & 53,1 & $46-50$ \\
\hline 500 & 100 & 54,6 & $36-39$ & 54,7 & $47-50$ & 52,5 & $34-37$ & 52,8 & $46-49$ \\
\hline 1000 & 100 & 51,9 & $27-30$ & 56,9 & $40-43$ & 51,4 & $30-31$ & 49,5 & $36-37$ \\
\hline 2000 & 100 & 44,2 & 24 & 52,8 & $38-40$ & 40,8 & $21-23$ & 41,8 & $29-31$ \\
\hline 4000 & 100 & 42,4 & $20-21$ & 43,2 & $23-26$ & 39,4 & $18-20$ & 40,9 & $21-25$ \\
\hline
\end{tabular}

TABEL III: Nilai NR, diambil dengan 2 sumber bunyi $90 \mathrm{~dB}$ dan $100 \mathrm{~dB}$

\begin{tabular}{lcccc}
\hline \hline Frekuensi (Hz) & \multicolumn{2}{c}{ NR Kaca 6 mm } & \multicolumn{2}{c}{ NR Triplek 6 mm } \\
& $90 \mathrm{~dB}$ & $100 \mathrm{~dB}$ & $90 \mathrm{~dB}$ & $100 \mathrm{~dB}$ \\
\hline All & 23,8 & 26,5 & 14,6 & 15,5 \\
250 & 23,9 & 23,8 & 12,7 & 12,8 \\
500 & 30,1 & 29,5 & 17,3 & 16,7 \\
1000 & 40,6 & 40,6 & 29,6 & 29,7 \\
2000 & 51 & 50,9 & 40,9 & 40,4 \\
4000 & 43,9 & 44,1 & 37,9 & 37,9 \\
& & & & \\
\hline \hline
\end{tabular}

[1] Ferdy A. 2012. "Pembuatan Alat Ukur Daya Isolasi Bahan". Studi Literatur. Fisika FMIPA ITS Surabaya.

[2] ASTM E 2611-09, Standard Test Method for Measurement of Normal Incidence Sound Transmission of Acoustical Materials based on the Transfer Matrix Method, American Society for Testing Material, 2009.

[3] L.L. Baranek, Acoustics (part XXV, Sound Transmision, McGraw-Hill Book Company Inc., New York, 1954).
[4] L.L. Doelle, Akustik Lingkungan (terjemahan Lea Prasetio, Erlangga., Jakarta, 1993)

[5] L. Prasetio, Akustik (Diktat Kuliah, Jurusan Fisika FMIPA ITS, Surabaya, 2003).

[6] P.S. Allan, et al., Polymer Testing, 31, 312-321 (2011).

[7] S.S. Jung, et al., Journal of the Korea Physical Society, 53, 596600 (2008). 